\title{
A highly permeable polyimide with enhanced selectivity for membrane gas separations $\uparrow$
}

Cite this: J. Mater. Chem. A, 2014, 2, 4874

Received 31st January 2014 Accepted 20th February 2014

DOI: $10.1039 / c 4 t a 00564 c$

www.rsc.org/MaterialsA

\author{
Yulia Rogan, ${ }^{a}$ Richard Malpass-Evans, ${ }^{a}$ Mariolino Carta, ${ }^{\mathrm{b}}$ Michael Lee, ${ }^{\mathrm{b}}$ \\ Johannes C. Jansen, ${ }^{* c}$ Paola Bernardo, ${ }^{c}$ Gabriele Clarizia, ${ }^{\mathrm{c}}$ Elena Tocci, ${ }^{c}$ Karel Friess, ${ }^{d}$ \\ Marek Lančd and Neil B. McKeown ${ }^{\star b}$
}

\begin{abstract}
A highly gas permeable polyimide with improved molecular sieving properties is produced by using a bisanhydride monomer based on the rigid ethanoanthracene unit. The polymer (PIM-PI-EA) demonstrates enhanced selectivity for gas separations so that its gas permeability data lie above the 2008 Robeson upper bounds for the important $\mathrm{O}_{2}-$ $\mathrm{N}_{2}, \mathrm{H}_{2}-\mathrm{N}_{2}, \mathrm{CO}_{2}-\mathrm{CH}_{4}$ and $\mathrm{CO}_{2}-\mathrm{N}_{2}$ gas pairs.
\end{abstract}

Polymers that can be processed from solution to form microporous solids are of growing interest for use as highly permeable membranes for gas separations including $\mathrm{O}_{2}$ or $\mathrm{N}_{2}$ enrichment from air, natural gas upgrading (predominantly removing $\mathrm{CO}_{2}$ from $\mathrm{CH}_{4}$ ), and hydrogen recovery from ammonia manufacture (separating $\mathrm{H}_{2}$ from $\mathrm{N}_{2}$ ). ${ }^{1-3}$ Polymers currently used as membranes for commercial gas separation, such as the polyimide Matrimid, ${ }^{4}$ generally demonstrate high selectivity but low permeability thus limiting industrial membrane applications to small and medium-scale gas separations. In contrast, highly permeable polymers have potential for large-scale separations but only if selectivity can be enhanced. ${ }^{3}$ However, for the separation of two gases ( $\mathrm{x}$ and $\mathrm{y}$ ), there is a well-established empirical trade-off between permeability $\left(P_{\mathrm{x}}\right)$ and selectivity $\left(\alpha_{\mathrm{xy}}=P_{\mathrm{x}} / P_{\mathrm{y}}\right)$ that was quantified by Robeson initially in 1991 (ref. 5) and then updated in $2008 .^{6}$ Based on the permeability data for a large number of polymers, Robeson identified an "upper bound" in plots of $\log P_{\mathrm{x}}$ versus $\log \alpha_{\mathrm{xy}}$ for each gas pair of interest. The position of a polymer's gas permeability data relative to the relevant upper bound is

${ }^{a}$ School of Chemistry, Cardiff University, Cardiff, CF10 2AT, UK

${ }^{b}$ EaStCHEM and School of Chemistry, University of Edinburgh, West Mains Road, Edinburgh EH9 3JJ, Scotland, UK. E-mail: neil.mckeown@ed.ac.uk

'Institute on Membrane Technology, ITM-CNR, c/o University of Calabria, Via P. Bucci 17/C, 87036 Rende, CS, Italy

${ }^{d}$ Institute of Chemical Technology, Department of Physical Chemistry, Technická 5, Prague 6, 166 28, Czech Republic

$\dagger$ Electronic supplementary information (ESI) available: Experimental details for synthesis, characterisation and modeling. Also sorption isotherms for $\mathrm{CO}_{2}, \mathrm{CH}_{4}$ and $\mathrm{N}_{2}$ and comparative permeability data for PIM-1, PIM-PI-SBI and PIM-EA-TB. See DOI: 10.1039/c4ta00564c used as the universal performance indicator for assessing its potential for the separation of two gases.

Robeson noted ${ }^{6}$ that each of the upper bounds are populated by data from glassy polymers with rigid chains that promote diffusivity selectivity - i.e. the preferential transport of lighter gas molecules of smaller kinetic diameters (e.g. $\mathrm{He}=$ 2.65; $\mathrm{H}_{2}=2.80 ; \mathrm{CO}_{2}=3.3 ; \mathrm{O}_{2}=3.45 \AA$ ) over that of larger molecules $\left(\right.$ e.g. $\left.\mathrm{N}_{2}=3.64 ; \mathrm{CH}_{4}=3.87 \AA\right)$. Hence it was predicted that greater size selectivity could be obtained by increasing polymer chain rigidity whereas high gas permeability relies on large inter-chain separation. ${ }^{7}$ Polymers of Intrinsic Microporosity (PIMs), such as the archetypal PIM-1 (Fig. 1a), fulfil both of these design criteria by possessing a rigid chain structure within which motion is restricted and sites of contortion, often provided by spirobisindan (SBI) units, to prohibit space efficient packing and generate high free volume. ${ }^{2,8-10}$ Therefore, permeability data for PIMs generally lie over the 1991 upper bound for most gas pairs ${ }^{10,11}$ and some approach, or even exceed, the 2008 upper bounds (Fig. 2). ${ }^{12,13}$ Similarly, microporous polyimides based on the SBI unit also demonstrate high permeability with modest selectivity (e.g. PIM-PI-SBI; Fig. 1b)..$^{14,15}$
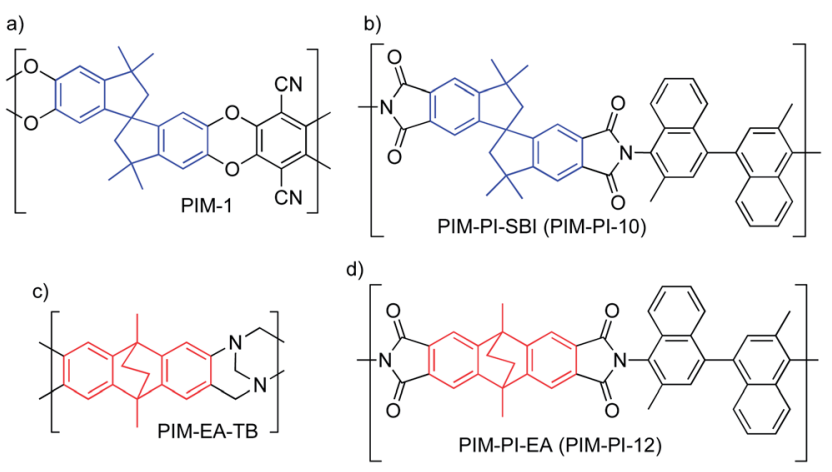

Fig. 1 The molecular structures of (a) PIM-1; (b) PIM-PI-SBI; (c) PIMEA-TB and (d) PIM-PI-EA. Spirobisindan (SBI) is blue, ethanoanthracene (EA) is red. 

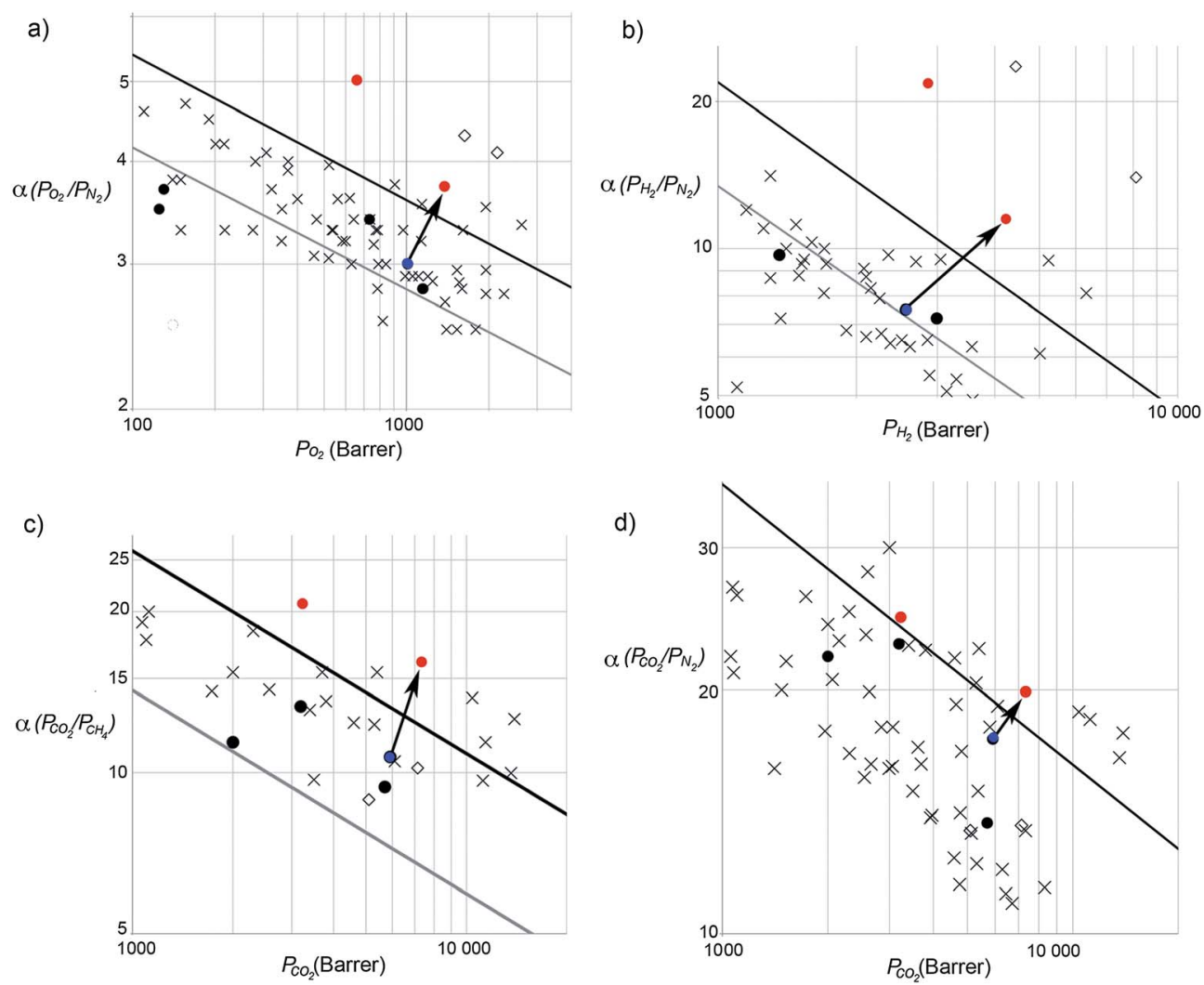

Fig. 2 Robeson plots for (a) $\mathrm{O}_{2}-\mathrm{N}_{2}$; (b) $\mathrm{H}_{2}-\mathrm{N}_{2}$; (c) $\mathrm{CO}_{2}-\mathrm{CH}_{4}$ and (d) $\mathrm{CO}_{2}-\mathrm{N}_{2}$ gas pairs showing the data for methanol treated $72 \mu \mathrm{m}$ film of PIM-PI-EA. The data point at lower permeability and higher selectivity in each plot is for the same film aged for 273 days. Data points are for other PIM-PIs with the arrows starting from the data point for PIM-PI-SBI (ESI Table $1 \uparrow$ ) representing the enhancement in performance on exchanging the SBI for EA units. The gray and black lines represent the 1991 and 2008 upper bounds, respectively. Data points $\diamond$ are for PIM-EATB. Also shown are data points $\times$ of other PIMs. PIMs that demonstrate data that cross various upper bounds are reported in ref. 9, 12, 13 and 16 .

Recently, we demonstrated that the polymerisation of 2,6(7)diamino-9,10-dimethylethanoanthracene by the formation of linking groups based on Tröger's base (TB) provides a highly permeable polymer (PIM-EA-TB; Fig. 1c) with remarkably high gas selectivities so that its data lie well above the 2008 upper bounds for $\mathrm{O}_{2}-\mathrm{N}_{2}$ (Fig. 2a), $\mathrm{H}_{2}-\mathrm{N}_{2}$ (Fig. 2b), $\mathrm{H}_{2}-\mathrm{CH}_{4}$ and $\mathrm{H}_{2}-$ $\mathrm{CO}_{2}{ }^{16}$ The exceptional performance of PIM-EA-TB was attributed to enhanced diffusivity selectivity as a result of its highly shape-persistent structure provided by the bridged bicyclic ethanoanthracene (EA) component as compared to the more flexible SBI unit. ${ }^{16}$ Hence it is important to establish whether the exchange of SBI components for EA units in other types of PIMs may also result in enhanced size-selectivity for gas separations and provides a general concept for improving polymers for gas separations. ${ }^{17}$ Here we validate this concept by the synthesis of an EA-based polyimide (PIM-PI-EA; Fig. 1d), which has a structure that allows the direct comparison of its performance with a recently reported highly permeable SBI-based polyimide (PIM-PI-SBI; Fig. 1b). ${ }^{14}$

The required novel EA-based bisanhydride monomer 1 was prepared from 2,3,6,7,9,10-hexamethylethanoanthracene ${ }^{18}$ and reacted with commercially available 3,3'-dimethylnaphthidine, a monomer of previous utility for preparing highly gas permeable polyimides (Scheme 1 and ESI $\dagger$ ). ${ }^{14,15}$ The resulting polymer, PIM-
PI-EA, was obtained in $88 \%$ yield and proved freely soluble in chloroform and THF, which facilitated its characterisation by ${ }^{1} \mathrm{H}$ NMR spectroscopy and Gel permeation chromatography (GPC). The latter indicated that PIM-PI-EA was of very high average molecular mass $\left(M_{\mathrm{w}}=340000 ; M_{\mathrm{n}}=110000 \mathrm{~g} \mathrm{~mol}^{-1}\right)$ as calibrated against polystyrene standards. Consequently, cast films of PIM-PI-EA from chloroform solution proved robust and suitable for gas permeability measurements. Nitrogen adsorption<smiles>Cc1cc2c(cc1C)C1(C)c3cc(C)c(C)cc3C2(C)c2cc(C)c(C)cc21</smiles>

Scheme 1 Synthesis of PIM-PI-EA. Reagents and conditions. (i) $\mathrm{KMnO}_{4}$, pyridine, $\mathrm{H}_{2} \mathrm{O}$, reflux $21 \mathrm{~h}$. (ii) $\mathrm{Ac}_{2} \mathrm{O}$, reflux, $17 \mathrm{~h}$. (iii) EtOH, TEA, reflux, 3 h. (iv) 3,3'-Dimethylnaphthidine, NMP, o-DCB, $195^{\circ} \mathrm{C}, 140 \mathrm{~h}$. 
isotherms for a powdered sample of PIM-PI-EA at $77 \mathrm{~K}$ showed significant uptake at low relative pressures indicative of intrinsic microporosity and provided an apparent BET surface area of 616 $\mathrm{m}^{2} \mathrm{~g}^{-1}$, which is lower than that of PIM-PI-SBI $\left(699 \mathrm{~m}^{2} \mathrm{~g}^{-1}\right)$.

The gas permeability data for a $72 \mu \mathrm{m}$ thick film of PIM-PI-EA are provided in Table 1 and the equivalent data for PIM-PI-SBI, PIM-1 and PIM-EA-TB are given in the ESI. $\dagger^{+14}$ Prior to analysis the film of PIM-PI-EA was treated by immersion in methanol as this is known to reverse the effects of physical ageing for glassy polymers and also removes the last residues of the casting solvent. ${ }^{9,12,16}$ Hence, this treatment allows a direct comparison between the gas permeabilities of different polymers.

The order of gas permeabilities for the freshly methanol treated film of PIM-PI-EA is $\mathrm{CO}_{2}>\mathrm{H}_{2}>\mathrm{He}>\mathrm{O}_{2}>\mathrm{CH}_{4}>\mathrm{N}_{2}$. This differs from most other PIMs including PIM-1 and PIM-PI-SBI in that $\mathrm{He}$ is faster than $\mathrm{O}_{2}$. It is notable that the value for $\mathrm{N}_{2}$ permeability through PIM-PI-EA is very similar to that of PIM-PISBI, whereas gases composed of smaller molecules $\left(\mathrm{He}, \mathrm{H}_{2}, \mathrm{CO}_{2}\right.$ and $\mathrm{O}_{2}$ ) are transported faster and $\mathrm{CH}_{4}$, composed of larger molecules, is transported significantly slower through PIM-PIEA relative to PIM-PI-SBI. These results validate the efficacy of the rigid ethanoanthracene unit as a component for inducing high gas selectivity via molecular sieving.

Importantly, the data points for PIM-PI-EA are above the Robeson upper bounds for $\mathrm{O}_{2}-\mathrm{N}_{2}$ (Fig. 2a), $\mathrm{H}_{2}-\mathrm{N}_{2}$ (Fig. 2b), $\mathrm{CO}_{2}-\mathrm{CH}_{4}$ (Fig. 2c), $\mathrm{CO}_{2}-\mathrm{N}_{2}$ (Fig. 2d) and $\mathrm{H}_{2}-\mathrm{CH}_{4}$ gas pairs, in contrast to those of PIM-PI-SBI, which fall below these upper bounds. The results for the $\mathrm{CO}_{2}-\mathrm{CH}_{4}$ and $\mathrm{CO}_{2}-\mathrm{N}_{2}$ gas pairs are particularly encouraging, as the equivalent data for the ethanoanthracene-containing PIM-EA-TB are anomalously poor and fall below the relevant upper bounds. ${ }^{16}$

Physical ageing (i.e. loss of free volume and gas permeability over time) is a general feature of glassy polymers ${ }^{\mathbf{1 9}}$ and is observed for PIM-PI-EA (Table 1). However, the loss of permeability due to aging is matched by a commensurate increase in selectivity so that the data points for the polymer aged for 273 days all lie above the upper bounds for $\mathrm{O}_{2}-\mathrm{N}_{2}$ (Fig. 2a), $\mathrm{H}_{2}-\mathrm{N}_{2}$ (Fig. 2b), $\mathrm{CO}_{2}-\mathrm{CH}_{4}$ (Fig. 2c), $\mathrm{CO}_{2}-\mathrm{N}_{2}$ (Fig. 2d) and $\mathrm{H}_{2}-\mathrm{CH}_{4}$ gas pairs. For the $\mathrm{O}_{2}-\mathrm{N}_{2}$ gas pair, the selectivity in favour of $\mathrm{O}_{2}$ of 5.0 for a value of $P_{\mathrm{O}_{2}}$ greater than 600 barrer is exceptional.

According to the solution-diffusion model, the permeability of a gas through a polymer is dependent on both its diffusivity $\left(D_{\mathrm{x}}\right)$ and its solubility $\left(S_{\mathrm{x}}\right)$ (i.e., $\left.P_{\mathrm{x}}=D_{\mathrm{x}} S_{\mathrm{x}}\right){ }^{20}$ The enhanced permeability of $\mathrm{He}, \mathrm{H}_{2}$ and $\mathrm{O}_{2}$ is attributable to greater diffusivity $\left(D_{\mathrm{x}}\right)$ within PIM-PI-EA, whereas, the enhanced permeability of $\mathrm{CO}_{2}$ appears to be related to its greater solubility in PIM-PI-EA as compared to PIM-PI-SBI (Table 1 and ESI Table $1 \dagger)$, as demonstrated by $\mathrm{CO}_{2}$ sorption isotherms measured at 298 K. (ESI Fig. 1a $\dagger$ ). The solubility of $\mathrm{CH}_{4}$ within PIM-PI-EA and PIM-PI-SBI (ESI Fig. 1b $\dagger$ ) is very similar. Therefore, the impressive potential of PIM-PI-EA for the commercially important $\mathrm{CO}_{2}-\mathrm{CH}_{4}$ separation is due to both enhanced diffusivity selectivity and solubility selectivity. $\mathrm{CO}_{2}$ sorption is higher in PIM-PI-SBI than in PIM-1, but not as high as in PIM-EA-TB, where the tertiary amine groups of the Tröger's base appear to contribute to the affinity for $\mathrm{CO}_{2}$ (ESI Fig. $\left.1 \mathrm{a} \dagger\right) .{ }^{21}$

Molecular modelling, which is the only technique which can visualize the free volume distribution, supports these findings. ${ }^{22,23}$ The high rigidity of the polymer structure is reflected in the difficulty to pack the polymer models. Fig. 3 shows the free volume in a PIM-PI-EA model, packed and equilibrated at the measured film density of $1.1 \mathrm{~g} \mathrm{~cm}^{-3}$. The small $o$-positronium probe gains access to the highly interconnected void structure. The $\mathrm{H}_{2}$ molecule is able to access more free volume than the larger $\mathrm{N}_{2}$. For $\mathrm{H}_{2}$ the $\mathrm{FV}$ is also more interconnected than for the $\mathrm{N}_{2}$ probe. This explains the higher diffusivity of $\mathrm{H}_{2}$ as compared to $\mathrm{N}_{2}$ found experimentally (Table 1 ).

From a fundamental perspective, this study provides a direct comparison between structurally related polyimides PIM-PI-EA and PIM-PI-SBI and demonstrates the advantage of the rigid bridged bicyclic ethanoanthracene over the more flexible and often used spirobisindane for enhancing diffusivity selectivity. ${ }^{16,22}$ In

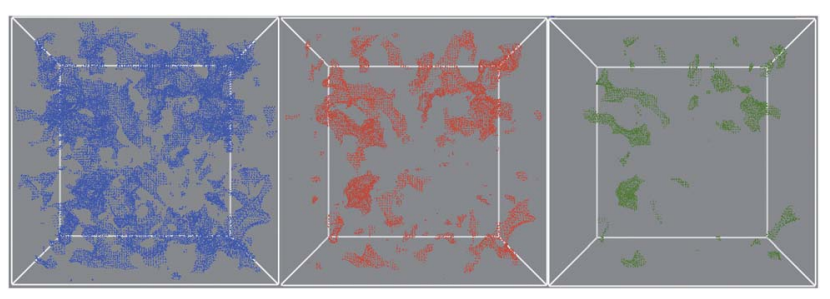

Fig. 3 Representation of the free volume distribution in a 3D box model of PIM-PI-EA, packed down to a density of $1.1 \mathrm{~g} \mathrm{~cm}^{-3}$. The blue, red and green shaded areas highlight the accessible free volume when probing with o-positronium, hydrogen and nitrogen probes, respectively.

Table 1 The gas permeabilities $P_{x}$ diffusivity $D_{x}$, solubility coefficient $S_{x}$ and ideal selectivities $\alpha\left(P_{x} / P_{\mathrm{N}_{2}}\right)$ for a methanol treated film of PIM-PI-EA of thickness $=72 \mu \mathrm{m}$ with comparable data for a the same film obtained after 273 days given in parentheses

\begin{tabular}{|c|c|c|c|c|c|c|}
\hline & $\mathrm{N}_{2}$ & $\mathrm{O}_{2}$ & $\mathrm{CO}_{2}$ & $\mathrm{CH}_{4}$ & $\mathrm{H}_{2}$ & $\mathrm{He}$ \\
\hline$P_{\mathrm{x}}^{a}$ & 369 (131) & 1380 (659) & $7340(3230)$ & 457 (156) & $4230(2860)$ & $1580(1130)$ \\
\hline$\alpha^{b}$ & $-(-)$ & $3.7(5.0)$ & 19.9 (24.6) & $1.2(1.2)$ & $11.5(21.8)$ & $4.3(8.6)$ \\
\hline$D_{\mathrm{x}} / D_{\mathrm{N}_{2}}$ & - & $3.2(4.8)$ & $1.1(1.6)$ & $0.29(0.28)$ & $40^{e}(120)$ & $60^{e}(191)$ \\
\hline$S_{\mathrm{x}}^{d{ }^{d}}$ & $3.29(3.3)$ & $3.83(3.4)$ & $57.8(50.1)$ & $14.2(13.5)$ & $\leq 0.94(0.60)$ & $\leq 0.23$ \\
\hline$S_{\mathrm{x}} / S_{\mathrm{N}_{2}}$ & - & $1.2(1.1)$ & $17.6(15.2)$ & $4.3(4.1)$ & $0.29(0.18)$ & $0.07(0.04)$ \\
\hline
\end{tabular}

${ }^{a}$ Units $=$ barrer. ${ }^{b} \alpha=\left(P_{\mathrm{x}} / P_{\mathrm{N}_{2}}\right) \cdot{ }^{c}$ Units $=10^{-12} \mathrm{~m}^{2} \mathrm{~s}^{-1} \cdot{ }^{d}$ Units $=\mathrm{cm}^{3} \mathrm{~cm}^{-3} \mathrm{bar}^{-1}$. ${ }^{e}$ For He and $\mathrm{H}_{2}$ the time lag is too short (<1 $\left.\mathrm{s}\right)$ for determination of $D$ with error $<10 \%$, and the value of $D$ is the minimum limit. 
addition, PIM-PI-EA has gas permeability data that lie well above the Robeson upper bounds for important gas pairs including $\mathrm{CO}_{2}-$ $\mathrm{CH}_{4}$, of interest for natural gas upgrading, and $\mathrm{CO}_{2}-\mathrm{N}_{2}$, of interest for post-combustion carbon capture applications. ${ }^{24}$ This significant enhancement of gas selectivity for highly permeable polyimides is of particular importance as polyimides are the most studied class of polymer for membrane applications. ${ }^{25}$ Therefore, methodologies that have been developed for polyimide membrane technology (e.g. cross-linking strategies) ${ }^{26}$ can also be applied to PIM-PI-EA, thus making it a strong candidate for exploitation as a membrane material.

\section{Acknowledgements}

European Community's Seventh Framework Programme (FP7/ 2007-2013) under grant agreement no. NMP3-SL-2009-228631 "DoubleNanoMem", the Italian Programma Operativo Nazionale Ricerca e Competitività 2007-2013, project PON01_01840 "MicroPERLA". The authors are also thankful for financial support of the Grant Agency of Czech Republic (Grants no. 106/ 10/1194).

\section{Notes and references}

1 (a) P. Bernardo, E. Drioli and G. Golemme, Ind. Eng. Chem. Res., 2009, 48, 4638; (b) D. E. Sanders, Z. P. Smith, R. Guo, L. M. Robeson, J. E. McGrath, D. R. Paul and B. D. Freeman, Polymer, 2013, 54, 4729; (c) Y. Yampolskii, Macromolecules, 2012, 45, 3298; (d) J. K. Adewole, A. L. Ahmad, S. Ismail and C. P. Leo, Int. J. Greenhouse Gas Control, 2013, 17, 46; (e) R. W. Baker and K. Lokhandwala, Ind. Eng. Chem. Res., 2008, 47, 2109; (f) C. A. Scholes, G. W. Stevens and S. E. Kentish, Fuel, 2012, 96, 15; $(g)$ R. S. Murali, T. Sankarshana and S. Sridhar, Sep. Purif. Rev., 2013, 42, 130.

2 N. B. McKeown and P. M. Budd, in Encyclopedia of Membrane Science and Technology, ed. E. M. V. Koek and V. V. Tarabara, John Wiley \& Sons, Inc., 2013, vol. 2, p. 781.

3 P. M. Budd and N. B. McKeown, Polym. Chem., 2010, 1, 63. 4 (a) W. F. Yong, F. Y. Li, Y. C. Xiao, T. S. Chung and Y. W. Tong, J. Membr. Sci., 2013, 443, 156; (b) Y. Huang and D. R. Paul, Ind. Eng. Chem. Res., 2007, 46, 2342.

5 L. M. Robeson, J. Membr. Sci., 1991, 62, 165.

6 L. M. Robeson, J. Membr. Sci., 2008, 320, 390.

7 (a) B. D. Freeman, Macromolecules, 1999, 32, 375; (b) L. M. Robeson, B. D. Freeman, D. R. Paul and B. W. Rowe, J. Membr. Sci., 2009, 341, 178.

8 (a) N. B. McKeown and P. M. Budd, Macromolecules, 2010, 43, 5163; (b) N. B. McKeown and P. M. Budd, Chem. Soc. Rev., 2006, 35, 675; (c) P. M. Budd, B. S. Ghanem, S. Makhseed, N. B. McKeown, K. J. Msayib and C. E. Tattershall, Chem. Commun., 2004, 230; (d) P. M. Budd, E. S. Elabas, B. S. Ghanem, S. Makhseed, N. B. McKeown, K. J. Msayib, C. E. Tattershall and D. Wang, Adv. Mater., 2004, 16, 456; (e) M. Carta, K. J. Msayib, P. M. Budd and N. B. McKeown, Org. Lett., 2008, 10, 2641; (f) A. V. Maffei, P. M. Budd and N. B. McKeown, Langmuir, 2006, 22, 4225.
9 P. M. Budd, N. B. McKeown, B. S. Ghanem, K. J. Msayib, D. Fritsch, L. Starannikova, N. Belov, O. Sanfirova, Y. P. Yampol'skii and V. Shantarovich, J. Membr. Sci., 2008, 325, 851.

10 P. M. Budd, K. J. Msayib, C. E. Tattershall, B. S. Ghanem, K. J. Reynolds, N. B. McKeown and D. Fritsch, J. Membr. Sci., 2005, 251, 263.

11 B. S. Ghanem, N. B. McKeown, P. M. Budd and D. Fritsch, Macromolecules, 2008, 41, 1640.

12 C. G. Bezzu, M. Carta, A. Tonkins, J. C. Jansen, P. Bernardo, F. Bazzarelli and N. B. McKeown, Adv. Mater., 2012, 24, 5930.

13 N. Du, H. B. Park, G. P. Robertson, M. M. Dal-Cin, T. Visser, L. Scoles and M. D. Guiver, Nat. Mater., 2011, 10, 372.

14 Y. Rogan, L. Starannikova, V. Ryzhikh, Y. Yampolskii, P. Bernardo, F. Bazzarelli, J. C. Jansen and N. B. McKeown, Polym. Chem., 2013, 4, 3813.

15 (a) B. S. Ghanem, N. B. McKeown, P. M. Budd, N. M. AlHarbi, D. Fritsch, K. Heinrich, L. Starannikova, A. Tokarev and Y. Yampolskii, Macromolecules, 2009, 42, 7881; (b) B. S. Ghanem, N. B. McKeown, P. M. Budd and D. Fritsch, Adv. Mater., 2008, 20, 2766.

16 M. Carta, R. Malpass-Evans, M. Croad, J. C. Jansen, P. Bernardo, F. Bazzarelli and N. B. McKeown, Science, 2013, 339, 303.

17 A PIM derived from 2,3,6,7-tetrahydroxyethanoanthracene and prepared using the same dioxane-forming polymerisation reaction with 2,3,5,6-tetrafluoroterephthalonitrile as is used for making PIM-1 proved to be insoluble although copolymer has been investigated. See (a) T. Emmler, K. Heinrich, D. Fritsch, P. M. Budd, N. Chaukura, D. Ehlers, K. Ratzke and F. Faupel, Macromolecules, 2010, 43, 6075; (b) D. Fritsch, G. Bengtson, M. Carta and N. B. McKeown, Macromol. Chem. Phys., 2011, 212, 1137.

18 L. R. Barclay and R. A. Chapman, Can. J. Chem., 1965, 43, 1754. 19 (a) Y. Huang and D. R. Paul, Polymer, 2004, 45, 8377; (b) M. S. McCaig and D. R. Paul, Polymer, 2000, 41, 629.

20 J. G. Wijmans and R. W. Baker, J. Membr. Sci., 1995, 107, 1. 21 (a) A. Del Regno, A. Gonciaruk, L. Leay, M. Carta, M. Croad, R. Malpass-Evans, N. B. McKeown and F. Siperstein, Ind. Eng. Chem. Res., 2013, 52, 16939; (b) X. Zhu, D.-T. Chi-Linh, C. R. Murdock, K. M. Nelson, C. Tian, S. Brown, S. M. Mahurin, D. M. Jenkins, J. Hu, B. Zhao, H. Liu and S. Dai, ACS Macro Lett., 2013, 2, 660.

22 M. Heuchel, D. Fritsch, P. M. Budd, N. B. McKeown and D. Hofmann, J. Membr. Sci., 2008, 318, 84.

23 G. S. Larsen, P. Lin, K. E. Hart and C. M. Colina, Macromolecules, 2011, 44, 6944.

24 N. Y. Du, H. B. Park, M. M. Dal-Cin and M. D. Guiver, Energy Environ. Sci., 2012, 5, 7306.

25 (a) D.-J. Liaw, K.-L. Wang, Y.-C. Huang, K.-R. Lee, J.-Y. Lai and C.-S. Ha, Prog. Polym. Sci., 2012, 37, 907; (b) Y. Xiao, B. T. Low, S. S. Hosseini, T. S. Chung and D. R. Paul, Prog. Polym. Sci., 2009, 34, 561; (c) A. Y. Alentev, I. A. Ronova, B. V. Shchukin and Y. P. Yampolskii, Polym. Sci., Ser. A, 2007, 49, 217; (d) R. M. Huertas, A. Tena, A. E. Lozano, J. de Abajo, J. G. de la Campa and E. M. Maya, Polym. Degrad. Stab., 2013, 98, 743.

26 K. Vanherck, G. Koeckelberghs and I. F. J. Vankelecom, Prog. Polym. Sci., 2013, 38, 874. 